\title{
Cardiovascular risk factors and the concentration of asymmetric dimethylarginine
}

\author{
Paweł Gać, ${ }^{1,2, A, D, F}$, Małgorzata Poręba ${ }^{3,-}{ }^{3-F}$, Marta Jurdziak ${ }^{1, B-D, F}$, Ewa Trzmielewska ${ }^{1, B, E, F}$,

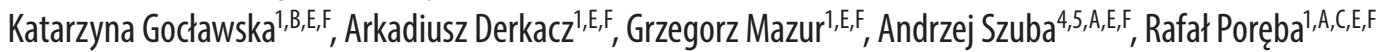 \\ ${ }^{1}$ Department of Internal Medicine, Occupational Diseases and Hypertension, Wroclaw Medical University, Poland \\ 2 Department of Hygiene, Wroclaw Medical University, Poland \\ ${ }^{3}$ Department of Pathophysiology, Wroclaw Medical University, Poland \\ ${ }^{4}$ Department of Internal Medicine, $4^{\text {th }}$ Military Hospital, Wrocław, Poland \\ ${ }^{5}$ Department of Angiology, Hypertension and Diabetology, Wroclaw Medical University, Poland \\ A - research concept and design; $B$ - collection and/or assembly of data; $C$ - data analysis and interpretation; \\ $D$ - writing the article; $E$ - critical revision of the article; $F$ - final approval of the article
}

Address for correspondence

Paweł Gać

E-mail: pawelgac@interia.pl

\section{Funding sources}

None declared

\section{Conflict of interest}

None declared

Received on 0ctober 21, 2018

Reviewed on June 13, 2019

Accepted on August 18, 2019

Published online on January 22, 2020

Cite as

Gać P, Poręba M, Jurdziak M, et al. Cardiovascular risk factors and the concentration of asymmetric dimethylarginine Adv Clin Exp Med. 2020;29(1):63-70. doi:10.17219/ acem/111808

DOI

10.17219/acem/111808

Copyright

Copyright by Author(s)

This is an article distributed under the terms of the

Creative Commons Attribution 3.0 Unported (CC BY 3.0)

(https://creativecommons.org/licenses/by/3.0/)

\begin{abstract}
Background. The most commonly recognized cardiovascular risk factors (CVRF) include smoking cigarettes, manifestation of arterial hypertension (AH), hypercholesterolemia, hypertriglyceridemia, manifestation of type 2 diabetes mellitus (DM), and the presence of overweight or obesity. In recent years, investigations have documented the significance of asymmetric dimethylarginine concentration (ADMA) in the pathogenesis of diseases affecting the cardiovascular system.

Objectives. To evaluate the relationship between the number of CVRF and blood ADMA concentration.

Material and methods. The study was conducted on a sample of 138 individuals (mean age $54.90 \pm 10.38$ years). Among the participants, we distniguished subgroups with no CVRF (group A, $n=21$ ), with 1-2 CVRF (group $B, n=53)$, with 3-4 CVRF (group $C, n=55$ ), and with 5-6 CVRF (group D, $n=9$ ). Plasma concentrations of arginine and of endogenous methylarginines were estimated.
\end{abstract}

Results. Plasma ADMA concentrations proved to be significantly higher in groups $B, C$ and D than those in group A. Regression analysis allowed us to demonstrate that in the studied population of patients, manifestation of type $2 \mathrm{DM}$, followed by AH and hypercholesterolemia, were linked to the highest probability of elevated plasma ADMA concentration.

Conclusions. Higher concentration of ADMA in the blood may be a marker for higher cardiovascular risk, especially associated with hypertension, type 2 DM and hypercholesterolemia.

Key words: type 2 diabetes mellitus, arterial hypertension, cardiovascular risk factors, endogenous methylarginines, asymmetric dimethylarginine 


\section{Introduction}

The most commonly recognized cardiovascular risk factors (CVRF) include smoking cigarettes, arterial hypertension $(\mathrm{AH})$, hypercholesterolemia, hypertriglyceridemia, type 2 diabetes mellitus (DM), and the presence of overweight or obesity. ${ }^{1}$ According to the World Health Organization (WHO), smoking cigarettes affected $21 \%$ of the world population $\geq 15$ years of life in 2012 (36\% men and 7\% women, in Poland around 26\% individuals). In 2014, $\mathrm{AH}$ was diagnosed in $22 \%$ of persons over 18 years of age worldwide (in Poland around 33.5\%, including 30.4\% of women and $36.8 \%$ of men). In 2008, hypercholesterolemia was present in about $39 \%$ of the world population and around $54 \%$ of the European population. ${ }^{2}$ According to the results of the WOBASZ study in Poland, elevated total cholesterol concentration was found in $67 \%$ of men and $64 \%$ of women. ${ }^{3}$ Patients with diabetes accounted for around 9\% of the world population; in Poland, 1,134,000 people had diabetes in 2000. On the other hand, obesity affected $13 \%$ of people worldwide in 2014; simultaneously, overweight was detected in $39 \%$ of people. In the European population, overweight was present in around $50 \%$ of women and men and obesity in $23 \%$ of women and $20 \%$ of men. ${ }^{2}$

Endogenous methylarginines represent products of arginine metabolism. Arginine residues in protein molecules may undergo post-translational modification, including methylation, involving the addition of 1 or 2 methyl groups to guanidine nitrogens of arginine, with the mediation of protein arginine methyl transferases (PRMTs). Two types of PRMTs are distinguished: type 1 catalyzes the addition of 2 methyl groups to a single guanidine residue, which results in the formation of the asymmetric dimethylarginine (ADMA). On the other hand, type 2 of PRMTs induces the addition of a single methyl group to each of the 2 guanidine residues, thus yielding a synthesis of symmetric dimethylarginine (SDMA). The 2 types of PRMT may also add a single methyl group, yielding $\mathrm{N}$-monomethyl-arginine (L-NMMA). In those reactions, S-adenosyl-methionine (SAM) serves as a donor of methyl groups, and the reaction product is S-adenosyl-homocysteine $(\mathrm{SAH})$. Following proteolysis, free L-NMMA, ADMA and SDMA are released to the cytosol. L-NMMA and ADMA act as competitive inhibitors for all 3 isoforms of nitrogen oxide synthase (NOS), while SDMA does not manifest such an activity. ${ }^{4,5}$ Nitrogen oxide synthase catalyzes conversion of L-arginine to citrulline and NO. Asymmetric dimethylarginine acts as the competitive inhibitor of NOS due to its competition with L-arginine. Asymmetric dimethylarginine and L-NMMA are eliminated from the body in part through the kidneys and also by enzymatic degradation with the mediation of enzymes, namely, the dimethylarginine dimethyl-aminohydrolases (DDAH). Symmetric dimethylarginine is almost completely eliminated through the kidneys. However, ADMA becomes eliminated mostly through enzymatic decomposition. Citrulline and dimethylamine are the products of enzymatic decomposition of ADMA. Nitrogen oxide (NO) is a direct inhibitor of DDAH, which probably provides a homeostatic mechanism, through which an increased concentration of NO may inhibit its further synthesis. ${ }^{4,5}$ Nitrogen oxide constitutes one of the main, endotheliumdependent vasoactive mediators, playing a principal role in the maintenance of tonus and the structure of vascular walls. In the cardiovascular system, NO is responsible for numerous activities such as endothelium-dependent vasodilation, inhibition of platelet aggregation, and inhibition of leukocyte adhesion and of smooth muscle cell proliferation. Moreover, NO manifests an anti-oxidative effect, which reduces the synthesis of superoxide radicals and oxidation of low-density lipoprotein (LDL) molecules. Since all the mechanisms are known as factors promoting the development of atherosclerosis, NO has been termed the anti-sclerotic molecule. ${ }^{6}$ Asymmetric dimethylarginine, due to its ability to inhibit synthesis of NO, is regarded to represent a marker of endothelial dysfunction. ${ }^{6}$

In recent years, investigations have documented the significance of endogenous methylarginines in the pathogenesis of cardiovascular system disease. Endogenous methylarginines concentration in blood has been evaluated in various diseases of the cardiovascular system, including in individuals with various CVRF. ${ }^{5-12}$ However, the available literature contains no unequivocal data related to the relationship between the coexistence of CVRF and the concentration of ADMA in the blood.

This study evaluated the relationship between the number of CVRF and blood ADMA concentration. Moreover, we have attempted to determine CVRF linked to the highest probability of elevated blood ADMA concentrations.

\section{Material and methods}

The studies were conducted on 138 individuals, 3979 years of age. Among the participants, men accounted for $33.33 \%$ (46 persons), and women for $66.67 \%$ (92 persons). The mean age in the study group was $54.90 \pm 10.38$ years. The general characteristics of the entire studied group are presented in Table 1.

The participants were subjected to questionnaire studies, after which basic anthropometric measurements were performed; arterial blood pressure was measured and routine blood tests were carried out, such as total cholesterol, triglycerides and glucose concentrations (Boehringer Mannheim GmbH, Mannheim, Germany). Also, concentrations of L-arginine and of endogenous methylarginines in plasma were estimated using high-performance liquid chromatography (HPLC). Arginine and its methyl derivatives were isolated from serum using a powerful cation exchanger: the mixture of concentrated ammonia, water and methanol in the volume ratios of 10:40:50 and, then, 
using o-phthalic aldehyde (OPA), in an alkaline medium, they were transformed to derivatives of fluorescent properties and separated using HPLC column (Symmetry C18 HPLC; Waters Co., Milford, USA). The separation and detection was conducted at room temperature using a fluorescence detector (Varian Pro Star 363, Varian Analytical Instruments, Walnut Creek, USA) (excitation: $340 \mathrm{~nm}$, emission: $455 \mathrm{~nm}$ ).

An anamnesis, physical examination and laboratory tests allowed us to characterize every participant in respect of CVRF, i.e., smoking habit, AH, hypercholesterolemia, hypertriglyceridemia, type $2 \mathrm{DM}$, and overweight/obesity. Cardiovascular risk factors have been evaluated, which, according to the INTERHEART study, account for $80 \%$ of the population risk. ${ }^{1}$

The active cigarette smoking habit was defined as a single cigarette smoked daily at least for the last year. Arterial hypertension was diagnosed in line with the Joint National Committee (JNC 8) recommendations, when a mean of 2 measurements amounted to $\geq 140 \mathrm{~mm} \mathrm{Hg}$ in the case of systolic blood pressure and/or $90 \mathrm{~mm} \mathrm{Hg}$ in the case of diastolic blood pressure. Hypercholesterolemia was diagnosed in cases when total cholesterol concentration was $\geq 200 \mathrm{mg} \%$. Hypertriglyceridemia was diagnosed when triglycerides concentration was $\geq 150 \mathrm{mg} \%$. Diabetes was diagnosed when incidental glycemia amounted to $\geq 200 \mathrm{mg} / \mathrm{dL}$ and it was accompanied by typical diabetic signs or when 2 separate measurements of fasting glycemia amounted to $\geq 126 \mathrm{mg} / \mathrm{dL}$, or when glycemia in the twohour glucose tolerance test with the use of 75 g glucose amounted to $\geq 200 \mathrm{mg} / \mathrm{dL}$. In a situation when a participant declared taking any hypotensive drugs, AH was diagnosed independently of the measured values of arterial blood pressure. Analogously, individuals taking hypolipidemic agents were qualified as patients with dyslipidemia and the patients taking hypoglycemic drugs as patients with DM. Overweight was diagnosed upon body mass index (BMI) values in the range of $25-30 \mathrm{~kg} / \mathrm{m}^{2}$ and obesity upon BMI values exceeding $30 \mathrm{~kg} / \mathrm{m}^{2}$.

On the basis of the number of detected CVRF, subgroups of participant were distinguished: 1 ) with no CVRF (group $\mathrm{A}, \mathrm{n}=21$ ), 2) with 1-2 CVRF (group $\mathrm{B}, \mathrm{n}=53$ ), 3) with 3-4 CVRF (group C, $n=55$ ), or 4) with 5-6 CVRF (group D, $\mathrm{n}=9$ ).

Written informed consent was obtained from all persons taking part in the study. The study was approved by the Wroclaw Medical University Ethics Committee.

The statistical analysis was conducted using the STATISTICA v. 12.0 (StatSoft Polska, Kraków, Poland) software. For quantitative variables, arithmetic means and standard deviations (SD) of the estimated parameters were calculated in the examined groups. Distribution of the variables was tested using the Lilliefors and W-Shapiro-Wilk tests. In cases involving quantitative variables manifesting the normal distribution, the subsequent statistical analysis involved a ttest for unlinked variables or analysis of variance (ANOVA) (unifactorial, parametric). The Mann-Whitney U test was applied in cases involving variables manifesting a distribution divergent from the normal one, whereas for quantitative variables the non-parametric equivalent of ANOVA or Kruskal-Wallis test was applied. Statistically significant differences between arithmetic means were detected using the Newman-Keuls post hoc test. For the quantitative variables, results were presented in the form of lists of percentages. For qualitative variables, in further statistical analysis, the Chi-square test of maximum likelihood was used. In order to define the relationship between studied variables, correlation and regression were analyzed. In the case involving quantitative variables manifesting the normal distribution, Pearson's r correlation coefficients were estimated, while in cases involving quantitative variables manifesting distribution divergent from the normal one, Spearman's r coefficients were calculated. Parameters of the model obtained in logistic analysis were estimated using the quasi-Newton method. Moreover, evaluations of the test accuracy were performed based on the receiver operating characteristic (ROC) curve analysis. Results at the level of $\mathrm{p}<0.05$ were accepted as statistically significant.

\section{Results}

Mean concentrations of $\mathrm{L}$-arginine, ADMA and SDMA in plasma of participants are presented in Table 1.

Concentrations of L-arginine and endogenous methylarginines in groups distinguished on the basis of single CVRF are presented in Table 2. When groups of patients differing in single CVRF were compared, ADMA concentration in plasma was demonstrated to be significantly higher in the following participants: those with AH as compared to participants with no $\mathrm{AH}$, among participants with hypercholesterolemia as compared to participants with no hypercholesterolemia, among participants with hypertriglyceridemia as compared to participants with no hypertriglyceridemia, and among participants with type $2 \mathrm{DM}$ as compared to participants with no type 2 DM. Moreover, the mean values of arginine/ADMA ratio were significantly lower among participants with $\mathrm{AH}$, as compared to participants with no $\mathrm{AH}$, in participants with hypercholesterolemia, as compared to participants with no hypercholesterolemia, and among participants with hypertriglyceridemia as compared to participants with no hypertriglyceridemia.

Concentrations of L-arginine and endogenous methylarginines in the groups distinguished on the basis of the number of detected CVRF are presented in Table 3. The comparative analysis of participant groups distinguished on the basis of the number of detected CVRF demonstrated that concentrations of ADMA in plasma were significantly higher in groups B, C and D than in group A. No significant differences were detected 
Table 1. Clinical and laboratory parameters in the study group

\begin{tabular}{|c|c|c|c|}
\hline Variable & Whole study group & Men & Women \\
\hline Number $^{\mathrm{a}}$ & $138 / 100.0$ & $46 / 33.3$ & $92 / 66.7$ \\
\hline Age $^{b}$ [years] & $54.90 \pm 10.38$ & $56.09 \pm 11.57$ & $55.30 \pm 9.40$ \\
\hline$B M I^{b}\left[\mathrm{~kg} / \mathrm{m}^{2}\right]$ & $26.23 \pm 2.70$ & $27.20 \pm 3.32$ & $25.75 \pm 2.19$ \\
\hline Overweight/obesity ${ }^{a}$ & $63 / 45.6$ & $23 / 50.0$ & $40 / 43.5$ \\
\hline Systolic blood pressure ${ }^{b}[\mathrm{~mm} \mathrm{Hg}]$ & $125.03 \pm 26.28$ & $124.67 \pm 28.62$ & $125.16 \pm 25.19$ \\
\hline Diastolic blood pressure ${ }^{b}[\mathrm{~mm} \mathrm{Hg}]$ & $74.82 \pm 13.46$ & $74.02 \pm 13.61$ & $75.22 \pm 13.44$ \\
\hline $\mathrm{AH}^{\mathrm{a}}$ & $56 / 40.5$ & $17 / 37.0$ & $39 / 42.4$ \\
\hline Total cholesterol ${ }^{b}$ mg/dL] & $164.68 \pm 39.07$ & $154.64 \pm 38.58$ & $169.69 \pm 38.54$ \\
\hline Triglycerides ${ }^{b}$ [mg/dL] & $122.53 \pm 66.86$ & $155.25 \pm 69.91$ & $106.67 \pm 59.38$ \\
\hline Hypercholesterolemia ${ }^{a}$ & $73 / 52.9$ & $27 / 58.7$ & $46 / 50.0$ \\
\hline Hypertriglyceridemia ${ }^{a}$ & $58 / 42.0$ & $17 / 37.0$ & $41 / 44.6$ \\
\hline Glucose $^{b}[\mathrm{mg} / \mathrm{dL}]$ & $103.28 \pm 15.14$ & $103.87 \pm 16.59$ & $102.98 \pm 14.45$ \\
\hline Diabetes mellitus ${ }^{a}$ & 16/11.6 & $5 / 10.9$ & $11 / 12.0$ \\
\hline Smoking ${ }^{a}$ & $54 / 39.1$ & 19/41.3 & $35 / 38.0$ \\
\hline Smoking years ${ }^{b}$ & $276.98 \pm 148.40$ & $309.71 \pm 163.93$ & $259.59 \pm 139.04$ \\
\hline $\mathrm{ADMA}^{\mathrm{b}}[\mu \mathrm{mol} / \mathrm{L}]$ & $1.15 \pm 0.70$ & $1.15 \pm 0.71$ & $1.16 \pm 0.69$ \\
\hline $\mathrm{SDMA}^{\mathrm{b}}[\mu \mathrm{mol} / \mathrm{L}]$ & $0.97 \pm 0.58$ & $0.88 \pm 0.50$ & $1.01 \pm 0.62$ \\
\hline Arginine $^{b}[\mu \mathrm{mol} / \mathrm{L}]$ & $22.66 \pm 6.94$ & $23.79 \pm 6.76$ & $22.10 \pm 7.00$ \\
\hline Arginine/ADMA ${ }^{b}$ & $24.59 \pm 12.63$ & $26.05 \pm 12.70$ & $23.85 \pm 12.60$ \\
\hline Arginine/SDMA ${ }^{b}$ & $28.99 \pm 14.65$ & $31.41 \pm 13.77$ & $27.78 \pm 14.99$ \\
\hline
\end{tabular}

a numbers/percentages; ${ }^{b}$ mean values \pm standard deviation (SD); ADMA - plasma asymmetric dimethylarginine concentration; BMI - body mass index; $\mathrm{AH}$ - arterial hypertension; SDMA - plasma symmetric dimethylarginine concentration; smoking years - number of cigarettes/24 $\mathrm{h} \times$ years of smoking

Table 2. L-arginine and endogenous methylarginines in groups distinguished on the basis of single risk factors of cardiovascular diseases

\begin{tabular}{|c|c|c|c|c|c|c|}
\hline Variable & $\begin{array}{c}\text { Presence } \\
\text { of the risk factor }\end{array}$ & $\mathrm{ADMA}^{\mathrm{a}}[\mu \mathrm{mol} / \mathrm{L}]$ & $\mathrm{SDMA}^{\mathrm{a}}[\mu \mathrm{mol} / \mathrm{L}]$ & $\begin{array}{l}\text { Arginine }^{\mathrm{a}} \\
{[\mu \mathrm{mol} / \mathrm{L}]}\end{array}$ & Arginine/ADMA ${ }^{\mathrm{a}}$ & Arginine/SDMA ${ }^{\mathrm{a}}$ \\
\hline \multirow{3}{*}{ Overweight/obesity } & yes & $1.17 \pm 0.66$ & $1.00 \pm 0.57$ & $22.82 \pm 7.31$ & $23.46 \pm 11.55$ & $28.66 \pm 15.33$ \\
\hline & no & $1.14 \pm 0.74$ & $0.94 \pm 0.59$ & $22.53 \pm 6.66$ & $25.53 \pm 13.47$ & $29.27 \pm 14.14$ \\
\hline & p-value & NS & NS & NS & NS & NS \\
\hline \multirow{3}{*}{$\mathrm{AH}$} & yes & $1.52 \pm 0.65$ & $0.88 \pm 0.51$ & $22.79 \pm 6.55$ & $22.32 \pm 11.31$ & $30.59 \pm 14.08$ \\
\hline & no & $0.90 \pm 0.73$ & $1.02 \pm 0.62$ & $22.58 \pm 7.24$ & $26.13 \pm 13.30$ & $27.90 \pm 15.01$ \\
\hline & $p$-value & 0.001 & NS & NS & 0.041 & NS \\
\hline \multirow{3}{*}{ Hypercholesterolemia } & yes & $1.28 \pm 0.72$ & $0.94 \pm 0.60$ & $22.99 \pm 7.20$ & $21.78 \pm 11.11$ & $30.06 \pm 14.80$ \\
\hline & no & $1.01 \pm 0.65$ & $1.00 \pm 0.56$ & $22.30 \pm 6.68$ & $27.73 \pm 13.55$ & $27.79 \pm 14.49$ \\
\hline & $p$-value & 0.020 & NS & NS & 0.005 & NS \\
\hline \multirow{3}{*}{ Hypertriglyceridemia } & yes & $1.35 \pm 0.76$ & $0.92 \pm 0.64$ & $22.97 \pm 7.90$ & $20.58 \pm 10.80$ & $31.58 \pm 16.03$ \\
\hline & no & $1.01 \pm 0.62$ & $1.00 \pm 0.53$ & $22.44 \pm 6.20$ & $27.49 \pm 13.12$ & $27.11 \pm 13.35$ \\
\hline & p-value & 0.005 & NS & NS & 0.001 & NS \\
\hline \multirow{3}{*}{ DM } & yes & $1.49 \pm 0.58$ & $0.86 \pm 0.56$ & $24.07 \pm 3.20$ & $23.21 \pm 12.04$ & $33.67 \pm 11.43$ \\
\hline & no & $1.11 \pm 0.61$ & $0.98 \pm 0.58$ & $22.48 \pm 7.28$ & $25.21 \pm 12.75$ & $28.37 \pm 14.95$ \\
\hline & $p$-value & 0.020 & NS & NS & NS & NS \\
\hline \multirow{3}{*}{ Smoking } & yes & $1.07 \pm 0.54$ & $1.00 \pm 0.55$ & $21.40 \pm 7.37$ & $23.14 \pm 11.33$ & $26.48 \pm 15.06$ \\
\hline & no & $1.21 \pm 0.78$ & $0.94 \pm 0.60$ & $23.48 \pm 6.57$ & $25.52 \pm 13.38$ & $30.60 \pm 14.24$ \\
\hline & $p$-value & NS & NS & NS & NS & NS \\
\hline
\end{tabular}

a mean values \pm standard deviation (SD); $\mathrm{AH}$ - arterial hypertension; DM - diabetes mellitus; ADMA - plasma asymmetric dimethylarginine concentration; NS - non significant; SDMA - plasma symmetric dimethylarginine concentration. 
Table 3. L-arginine and endogenous methylarginines in groups distinguished on the basis of the number of cardiovascular risk factors

\begin{tabular}{|c|c|c|c|c|c|c|}
\hline Group & Number of CVRF & $\mathrm{ADMA}^{\mathrm{a}}[\mu \mathrm{mol} / \mathrm{L}]$ & $\mathrm{SDMA}^{\mathrm{a}}[\mu \mathrm{mol} / \mathrm{L}]$ & Arginine $[\mu \mathrm{mol} / \mathrm{L}]$ & Arginine/ADMA ${ }^{a}$ & Arginine/SDMA ${ }^{a}$ \\
\hline$A(n=21)$ & 0 & $0.58 \pm 0.11$ & $0.98 \pm 0.51$ & $22.40 \pm 3.06$ & $39.98 \pm 9.60$ & $26.66 \pm 10.12$ \\
\hline$B(n=53)$ & $1-2$ & $1.32 \pm 0.78$ & $1.03 \pm 0.61$ & $22.56 \pm 8.11$ & $20.56 \pm 10.37$ & $27.65 \pm 16.01$ \\
\hline$C(n=55)$ & $3-4$ & $1.22 \pm 0.67$ & $0.93 \pm 0.62$ & $22.68 \pm 7.17$ & $22.55 \pm 11.70$ & $30.24 \pm 14.95$ \\
\hline$D(n=9)$ & $5-6$ & $1.12 \pm 0.52$ & $0.76 \pm 0.22$ & $23.83 \pm 5.09$ & $24.86 \pm 10.99$ & $34.66 \pm 13.10$ \\
\hline$p$-value & & $\begin{array}{l}\text { A vs B: } 0.002 \\
\text { A vs C: } 0.006 \\
\text { A vs D: } 0.009\end{array}$ & NS & NS & $\begin{array}{l}\text { A vs B: } 0.001 \\
\text { A vs C: } 0.001 \\
\text { A vs } D: 0.001\end{array}$ & NS \\
\hline
\end{tabular}

a mean values \pm standard deviation (SD); ADMA - plasma asymmetric dimethylarginine concentration; CVRF - cardiovascular risk factor; NS - non significant; SDMA - plasma symmetric dimethylarginine concentration.

Table 4. Results of estimation for model obtained in progressive step-wise multivariable analysis of regression. Model for ADMA $[\mu \mathrm{mol} / \mathrm{L}]$

\begin{tabular}{|l|c|c|c|c|c|}
\hline \multicolumn{1}{|c|}{ Variable } & $\begin{array}{c}\text { Regression } \\
\text { coefficient }\end{array}$ & SEM of Rc & p-value & $\begin{array}{c}\text { p-value } \\
\text { of the model }\end{array}$ & $\begin{array}{c}\text { SEM } \\
\text { of the model }\end{array}$ \\
\hline Intercept & 0.953 & 0.114 & 0.001 & \\
DM & 0.380 & 0.200 & 0.040 & 0.028 & \pm 0.680 \\
\hline AH & 0.355 & 0.193 & 0.037 & \\
\hline Hypercholesterolemia & 0.284 & 0.148 & 0.047 & & \\
\hline
\end{tabular}

ADMA - plasma asymmetric dimethylarginine concentration; $\mathrm{AH}$ - arterial hypertension; DM - diabetes mellitus; SEM of Rc - standard error of the mean of regression coefficient.

Table 5. The sensitivity and specificity of ADMA concentration as a predictor of CVRF number

\begin{tabular}{|c|c|c|c|c|c|}
\hline Variable & CVRF $\geq 1$ & CVRF $\geq 2$ & CVRF $\geq 3$ & CVRF $\geq 4$ & CVRF $\geq 5$ \\
\hline ADMA concentration as predictor of CVRF number [ $\mu \mathrm{mol} / \mathrm{L}]$ & $\geq 0.76$ & $\geq 0.78$ & $\geq 0.85$ & $\geq 0.95$ & $\geq 0.97$ \\
\hline Sensitivity & 0.952 & 0.719 & 0.554 & 0.530 & 0.519 \\
\hline Specificity & 0.786 & 0.792 & 0.672 & 0.652 & 0.778 \\
\hline Accuracy & 0.812 & 0.775 & 0.609 & 0.551 & 0.536 \\
\hline Positive predictive values & 0.444 & 0.511 & 0.661 & 0.884 & 0.971 \\
\hline Negative predictive values & 0.989 & 0.903 & 0.566 & 0.217 & 0.101 \\
\hline Likelihood ratios positive & 4.457 & 3.463 & 1.689 & 1.525 & 2.337 \\
\hline Likelihood ratios negative & 0.061 & 0.355 & 0.664 & 0.720 & 0.618 \\
\hline
\end{tabular}

ADMA - plasma asymmetric dimethylarginine concentration; CVRF - cardiovascular risk factor.

in ADMA concentrations in plasma between groups $B$, $\mathrm{C}$ and $\mathrm{D}$. Moreover, in groups $\mathrm{B}, \mathrm{C}$ and $\mathrm{D}$ mean values of arginine/ADMA quotient were significantly lower than in group $\mathrm{A}$.

An analysis of correlation revealed no linear relationship between the number of CVRF on the one hand, and concentrations of L-arginine and of endogenous methylarginines on the other. Nevertheless, significant linear relationships were detected: the positive one between ADMA concentration in plasma and cholesterol concentration in the blood $(\mathrm{r}=0.19, \mathrm{p}=0.023)$ and negative ones between the value of arginine/ADMA ratio and cholesterol concentration in the blood $(\mathrm{r}=-0.22, \mathrm{p}=0.007)$, and also between the value of arginine/ADMA ratio and triglyceride concentration in the blood $(\mathrm{r}=-0.18, \mathrm{p}=0.030)$.

Results of estimations using the model reflecting the regression analysis are presented in Table 4. In an analysis of multifactorial progressive stepwise regression, taking into account dichotomic, potentially independent variables, i.e., smoking of cigarettes, AH, hypercholesterolemia, hypertriglyceridemia, type $2 \mathrm{DM}$, and overweight/ obesity, the following model was obtained: ADMA $=0.953$ +0.380 type $2 \mathrm{DM}+0.355 \mathrm{AH}+0.284$ hypercholesterolemia \pm 0.680 . The model allowed us to conclude that, out of the evaluated CVRF, type $2 \mathrm{DM}$, followed by $\mathrm{AH}$ and hypercholesterolemia, were linked to the highest probability of elevated ADMA concentrations in plasma.

The sensitivity and specificity of ADMA concentration as a predictor of the CVRF number were presented in Table 5. The ROC analysis indicated ADMA concentration values constituting predictor conditions for the CVRF number, being for CVRF $\geq 1 \geq 0.76 \mu \mathrm{mol} / \mathrm{L}$, for CVRF $\geq 2 \geq 0.78 \mu \mathrm{mol} / \mathrm{L}$, for CVRF $\geq 3 \geq 0.85 \mu \mathrm{mol} / \mathrm{L}$, for CVRF $\geq 4 \geq 0.95 \mu \mathrm{mol} / \mathrm{L}$, and for CVRF $\geq 5 \geq 0.97 \mu \mathrm{mol} / \mathrm{L}$. The highest prediction sensitivity of $95.2 \%$ was demonstrated for the ADMA criterion $\geq 0.76 \mu \mathrm{mol} / \mathrm{L}$ as a predictor 
of the CVRF $\geq 1$ number, and the highest specificity equal to $79.2 \%$ for the ADMA criterion $\geq 0.78 \mu \mathrm{mol} / \mathrm{L}$ as a predictor of the CVRF $\geq 2$ number. In general, the highest prediction accuracy of $81.2 \%$ was obtained for the ADMA criterion $\geq 0.76 \mu \mathrm{mol} / \mathrm{L}$ as a predictor of CVRF $\geq 1$.

\section{Discussion}

We showed that higher blood ADMA levels may be the marker for higher cardiovascular risk. The comparative analyzes and the one-way analysis of dependencies (correlation analysis) demonstrated a relationship between selected CVRF and higher levels of ADMA in the blood. Higher levels of ADMA in the blood were observed in patients with hypertension, hypercholesterolemia, hypertriglyceridemia, and type 2 DM. A positive correlation between total cholesterol and ADMA concentration in the blood as well as negative correlations between total cholesterol and triglyceride concentrations and ADMA concentration in the blood were demonstrated. In the multivariate analysis of dependencies (regression analysis), it was confirmed that type $2 \mathrm{DM}$, hypertension and hypercholesterolemia are independently associated with higher levels of ADMA in the blood. Analysis of the dependency between CVRF and ADMA concentration in the blood indicated that in the context of ADMA concentration, the occurrence of the first CVRF is more important. Asymmetric dimethylarginine concentration in the blood was significantly higher in each group of patients with CVRF than in the group without CVRF. At the same time, there were no differences between the groups of patients with 1-2 CVRF, 3-4 CVRF and 5-6 CVRF. In addition, there was no linear dependency between CVRF and ADMA concentration in the blood, and the analysis of ROC curves and associations indicated the highest accuracy of the concentration criterion of ADMA $>0.76 \mu \mathrm{mol} / \mathrm{L}$ as a predictor of CVRF $\geq 1$.

The results of the current study are consistent with the previous reports regarding CVRF and ADMA blood concentration. At the same time, they fill the gap in literature in the context of the relationships between the number of CVRF and ADMA.

In patients with $A H$, representing the other important CVRF, the elevated ADMA concentrations were described. In one of the studies, significantly higher ADMA levels in patients with $\mathrm{AH}$ and cardiovascular complications were noted, and especially in individuals with uncontrolled or not appropriately controlled AH as compared to the control group. Additionally, concentrations of ADMA correlated positively with the traditional CVRF. ${ }^{13}$ Moreover, results obtained by Vallance et al. showed that in patients with renal failure, the AH developed significantly more frequently in patients with elevated blood ADMA level, ${ }^{4}$ while Fliser et al. ${ }^{14}$ and Schulze et al. ${ }^{15}$ could not detect any relationship between ADMA concentration and values of arterial blood pressure. The other investigations ${ }^{16,17}$ allowed us to clarify the distinct results obtained in various studies: it has been found that the presence of additional risk factors, such as age, insulin resistance, dyslipidemia, or administered drugs, may modify ADMA levels and in this way they may disturb the relationship between ADMA and arterial blood pressure. Results of studies conducted by Poręba et al. showed that mean concentrations of ADMA were significantly higher and the arginine/ADMA ratio was significantly lower in people with $\mathrm{AH}$ and co-existing leftventricular diastolic dysfunction (LVDD) as compared to the group without LVDD. Also, in the group of patients with AH diagnosed within the recent 5 years, similar relations were found. The independent factors of LVDD risk included higher concentrations of ADMA and LDL, higher values of BMI, of left ventricular myocardium (LVMI) and of higher mean arterial blood pressure. Thus, the authors proved that higher values of ADMA may carry a prognostic value in the context of the development of LVDD in individuals with $\mathrm{AH} .{ }^{18}$

An interesting publication by Achan et al. described the effects of intravenous administration of low ADMA dose on heart and systemic vascular resistance. In the study group consisting of 12 men without any serious disease, the application of ADMA caused a reduction in the heart rate and an decrease in cardiac output, and additionally an increase in mean arterial blood pressure and systemic vascular resistance. The effects resembled those detected in pathologies associated with accumulation of ADMA. ${ }^{19}$ Our study clearly confirmed the relationship between hypertension and higher levels of ADMA in blood.

In a couple of studies, the relationships between elevated ADMA levels and a range of pathologies were investigated and among them some seem to be important in the aspect of cardiovascular risk. In a group of patients with hypercholesterolemia, elevated concentrations of ADMA and decreased values of L-arginine/ADMA ratio were present. The increase in ADMA concentration was linked to the inhibited endothelium-dependent vasodilatation and reduced excretion of nitrates. ${ }^{9}$ In other reports, hypertriglyceridemia was accompanied by elevated levels of ADMA in a group of persons with insulin resistance, ${ }^{20}$ while in the group of patients with dyslipidemia, higher values of endothelial dysfunction markers such as ADMA as well as plasma viscosity and the level of oxidized LDL molecules were documented, together with lower NO levels. $^{21}$

Results of several investigations indicate that ADMA concentrations are higher in diabetics as compared to patients without DM. ${ }^{22,23}$ Higher levels of ADMA were described, as previously mentioned, also in persons with insulin resistance. ${ }^{20}$ Moreover, the data was then supported by the different studies in the group of diabetics, where higher concentrations of ADMA were linked to the progression of atherosclerosis and an elevated risk 
of cardiovascular events. Therefore, the conclusion was drawn that ADMA represents the independent marker of progression involving cardiovascular complications in diabetic patients. ${ }^{24-26}$ Nevertheless, the results of certain studies failed to confirm this relationship; for example, Anderssohn et al. and Böger et al. could not find the relationship between ADMA and cardiovascular events in diabetic patients. ${ }^{27,28}$ Such discrepancies may reflect the distinct activity of enzymes linked to the degradation of ADMA (DDAH), influenced by numerous variables: genetic lesions, including polymorphism of genes responsible for synthesis of DDAH 1 and DDAH2, presence of DM itself, and the applied hypoglycemic drugs. ${ }^{27}$ The other authors detected lower concentrations of ADMA and uric acid and, at the same time, higher levels of HbA1c, LDL-cholesterol and NO in 99 women with type $1 \mathrm{DM}$, as compared to the control group. The results, which seem to be completely distinct from the previously discussed, may reflect the selection of the investigated group, preferring women with type $1 \mathrm{DM}$ with no additional risk factors, probably affected by less pronounced oxidative stress, which could inhibit the activity of enzymes engaged in ADMA degradation, than in the groups subjected to other studies. ${ }^{29} \mathrm{Cur}$ rent studies confirm the relation between the occurrence of type 2 DM and higher levels of ADMA in the blood. Simultaneously, it should be noted that type 2 DM, when compared with various examined CVRF, proved to be the strongest predictor of higher ADMA levels in the blood in a regression analysis.

The results of the present study allow us to recognize higher levels of ADMA as an indicator of higher cardiovascular risk associated with the occurrence of recognized risk factors. However, the higher concentration of ADMA still cannot be considered as an independent CVRF. In the methodology of the current study, the data was collected at the same time in a single determination. To consider higher levels of ADMA in the blood as an independent CVRF, a long-term analysis with an assessment of long-term adverse cardiovascular events would be most appropriate.

In the light of previous publications, higher cardiovascular risk results mainly from endothelial dysfunction. Asymmetric dimethylarginine represents a competitive inhibitor of NOS. Nitrogen oxide performs a controlling function in several mechanisms of the cardiovascular system and, among others, it controls the tension of vascular walls; simultaneously, it is considered to be the principal factor linked to endothelium vasodilatation. Moreover, it controls the structure of vascular walls (inhibits smooth muscle proliferation) as well as interactions between cells of blood vessels (inhibiting adhesion and aggregation of platelets and adhesion of monocytes). Increased levels of ADMA lead to decreased concentrations of NO, abrogation of its biological functions and, in this way, to endothelial dysfunction. Endothelial dysfunction is linked to an elevated cardiovascular risk. ${ }^{10}$
In addition to the formerly discussed relationship between the CVRF number and ADMA blood concentration, the currently discussed study complements the existing scientific literature of the topic regarding the CVRF prediction attempts using a single determination of ADMA concentration. The results of the performed analyses indicated the highest accuracy of prediction (amounting to $81.2 \%$ ) for the ADMA criterion $\geq 0.76 \mu \mathrm{mol} / \mathrm{L}$ as a predictor of the CVRF $\geq 1$ number, although it should be noted that the accuracy levels in the range of $53.6-77.5 \%$ for other CVRF numbers also appear to be acceptable.

The current study is not devoid of several limitations. In the field of study material, a significant limitation is the number of patients examined. Despite the inclusion of 138 people in the study, in a comparative analysis, a subgroup of people with 5-6 CVRF is represented by only 9 people, which significantly limits the validity of the obtained results. The overrepresentation in the studied group of women, who accounted for $2 / 3$ of the respondents, is also worth noting. In the field of study methodology, the selection of analyzed CVRF may be considered controversial. When selecting them, the INTERHEART study criteria were used and those CVRF can attribute to $80 \%$ of the population risk. In addition, the study is limited by the single stage of measurements made and the data collected. Consequently, the results of the study only allow for the recognition of higher levels of ADMA as an indicator of higher cardiovascular risk.

\section{Conclusions}

A higher concentration of ADMA in the blood may be a marker for higher cardiovascular risk, especially associated with hypertension, type $2 \mathrm{DM}$ and hypercholesterolemia.

\section{ORCID iDs}

Paweł Gać (i) https://orcid.org/0000-0001-8366-0239 Małgorzata Poręba (1) https://orcid.org/0000-0002-4868-3088 Marta Jurdziak (1) https://orcid.org/0000-0001-7529-4822 Ewa Trzmielewska (1) https://orcid.org/0000-0002-2024-6011 Katarzyna Gocławska (1) https://orcid.org/0000-0002-2817-3291 Arkadiusz Derkacz (1) https://orcid.org/0000-0002-9231-7392 Grzegorz Mazur (1) https://orcid.org/0000-0003-0645-4997 Andrzej Szuba (1) https://orcid.org/0000-0002-7555-6201 Rafał Poręba (1) https://orcid.org/0000-0002-5109-8023

\section{References}

1. Yusuf S, Hawken S, Ounpuu S, et al; INTERHEART Study Investigators. Effect of potentially modifiable risk factors associated with myocardial infarction in 52 countries (the INTERHEART study): Case-control study. Lancet. 2004;364(9438):937-952.

2. WHO. Global Health Observatory (GHO) data. http://www.who.int/ gho/. Accessed June 12, 2017.

3. Pająk A, Wiercińska E, Polakowska M, et al. Prevalence of dyslipidemia in men and women between the ages of 20-74 in Poland. Results of the WOBASZ program [in Polish]. Kardiol Pol. 2005;63(6 Suppl 4): S620-S625.

4. Vallance P, Leiper J. Cardiovascular biology of the asymmetric dimethylarginine: Dimethylarginine dimethylaminohydrolase pathway. Arterioscler Thromb Vasc Biol. 2004;24(6):1023-1030. 
5. Böger RH, Zoccali C. ADMA: A novel risk factor that explains excess cardiovascular event rate in patients with end-stage renal disease. Atheroscler Suppl. 2003;4(4):23-28.

6. Böger $\mathrm{RH}$. The emerging role of asymmetric dimethylarginine as a novel cardiovascular risk factor. Cardiovasc Res. 2003;59(4):824-833.

7. Böger RH. Asymmetric dimethylarginine (ADMA) and cardiovascular disease: Insights from prospective clinical trials. Vasc Med. 2005 10(Suppl 1):S19-S25.

8. Böger RH. Asymmetric dimethylarginine (ADMA): A novel risk marker in cardiovascular medicine and beyond. Ann Med. 2006;38(2):126-136.

9. Böger RH, Bode-Böger SM, Szuba A, et al. Asymmetric dimethylarginine (ADMA): A novel risk factor for endothelial dysfunction: Its role in hypercholesterolemia. Circulation. 1998;98(18):1842-1847.

10. Tang WH, Wang Z, Cho L, Brennan DM, Hazen SL. Diminished global arginine bioavailability and increased arginine catabolism as metabolic profile of increased cardiovascular risk. J Am Coll Cardiol. 2009; 53(22):2061-2067.

11. Wang J, Sim AS, Wang XL, Salonikas C, Naidoo D, Wilcken DE. Relations between plasma asymmetric dimethylarginine (ADMA) and risk factors for coronary disease. Atherosclerosis. 2006;184(2):383-388.

12. Hov GG, Sagen E, Hatlen G, Bigonah A, Åsberg A, Aasarød K. Arginine/asymmetric dimethylarginine ratio and cardiovascular risk factors in patients with predialytic chronic kidney disease. Clin Biochem. 2011;44(8-9):642-646.

13. Tayeh O, Fahmi A, Islam M, Saied M. Asymmetric dimethylarginine as a prognostic marker for cardiovascular complications in hypertensive patients. Egyptian Heart J. 2011;63(2):117-124.

14. Fliser D, Kronenberg F, Kielstein JT, et al. Asymmetric dimethylarginine and progression of chronic kidney disease: The mild to moderate kidney disease study. J Am Soc Nephrol. 2005;16(8):2456-2461.

15. Schulze F, Maas R, Freese R, Schwedhelm E, Silberhorn E, Böger RH. Determination of a reference value for $N(G), N(G)$-dimethyl-L-arginine in 500 subjects. Eur J Clin Invest. 2005;35(10):622-626.

16. Bakris $G L$, Williams $M$, Dworkin $L$, et al. Preserving renal function in adults with hypertension and diabetes: A consensus approach. National Kidney Foundation Hypertension and Diabetes Executive Committees Working Group. Am J Kidney Dis. 2000;36(3):646-661.

17. Dayoub H, Achan V, Adimoolam S, et al. Dimethylarginine dimethylaminohydrolase regulates nitric oxide synthesis: Genetic and physiological evidence. Circulation. 2003:108(24):3042-3047.
18. Poręba R, Gać P, Poręba M, et al. Left ventricular diastolic dysfunction and plasma asymmetric dimethylarginine concentration in persons with essential hypertension. Arch Med Sci. 2015;11(3):521-529.

19. Achan V, Broadhead M, Malaki M, et al. Asymmetric dimethylarginine causes hypertension and cardiac dysfunction in humans and is actively metabolized by dimethylarginine dimethylaminohydrolase. Arterioscler Thromb Vasc Biol. 2003;23(8):1455-1459.

20. Stühlinger MC, Abbasi F, Chu JW, et al. Relationship between insulin resistance and an endogenous nitric oxide synthase inhibitor. JAMA. 2002;287(11):1420-1426.

21. Ercan M, Firtina S, Konukoglu D. Comparison of plasma viscosity as a marker of endothelial dysfunction with nitric oxide and asymmetric dimethylarginine in subjects with dyslipidemia. Clin Hemorheol Microcirc. 2014;57(4):315-323.

22. Abbasi F, Asagmi T, Cooke JP, et al. Plasma concentrations of asymmetric dimethylarginine are increased in patients with type 2 diabetes mellitus. Am J Cardiol. 2001;88(10):1201-1203.

23. Tarnow L, Hovind $\mathrm{P}$, Teerlink T, Stehouwer CD, Parving HH. Elevated plasma asymmetric dimethylarginine as a marker of cardiovascular morbidity in early diabetic nephropathy in type 1 diabetes. Diabetes Care. 2004;27(3):765-769.

24. Kanazawa I, Yano S, Notsu Y, Yamaguchi T, Nabika T, Sugimoto T. Asymmetric dimethylarginine as a risk factor for cardiovascular disease in Japanese patients with type 2 diabetes mellitus. Clin Endocrinol (Oxf). 2011;74(4):467-472.

25. Konya $\mathrm{H}$, Miuchi M, Satani K, et al. Asymmetric dimethylarginine, a biomarker of cardiovascular complications in diabetes mellitus. World J Exp Med. 2015;5(2):110-119.

26. Krzyzanowska K, Mittermayer F, Wolzt M, Schernthaner G. Asymmetric dimethylarginine predicts cardiovascular events in patients with type 2 diabetes. Diabetes Care. 2007;30(7):1834-1839.

27. Anderssohn M, McLachlan S, Lüneburg N, et al. Genetic and environmental determinants of dimethylarginines and association with cardiovascular disease in patients with type 2 diabetes. Diabetes Care. 2014;37(3):846-854.

28. Böger RH, Sullivan LM, Schwedhelm E, et al. Plasma asymmetric dimethylarginine and incidence of cardiovascular disease and death in the community. Circulation. 2009;119(12):1592-1600.

29. Pitocco D, Zaccardi F, Di Stasio E, et al. Role of asymmetric-dimethylL-arginine (ADMA) and nitrite/nitrate (NOx) in the pathogenesis of oxidative stress in female subjects with uncomplicated type 1 diabetes mellitus. Diabetes Res Clin Pract. 2009;86(3):173-176. 